\title{
CAPITAL EXCEDENTE E URBANIZAÇÃO \\ O Papel dos Grandes Projetos Urbanos
}

\author{
NADIA SOMEKH \\ RICARDO CARLOS GASPAR
}

R E S U M O O presente artigo desenvolve algumas reflexōes sobre a relação entre os grandes projetos urbanos, a absorção dos excedentes de capital e as crises econômicas da atualidade. Ele principia pela conceitualização dos grandes projetos urbanos à luz do novo papel das cidades na economia mundial contemporânea, prossegue com consideraçôes sobre a dinâmica imobiliária e a disputa em torno da terra e da renda do solo urbano, e finaliza com a defesa do papel do Estado - em todas as escalas geográficas, mas, sobretudo, do Estado nacional - no ordenamento do território, na fixação de princípios integrados de política regional e na regulação pública do espaço urbano.

P A L A V R A S - C H A V E Grandes projetos urbanos; excedentes de capital; politica urbana; Estado nacional; solo urbano.

\section{INTRODUÇÃO}

O último livro do geógrafo norte-americano David Harvey, recentemente publicado no Brasil, O enigma do capital e as crises do capitalismo (2011a), aborda uma dimensão essencial da economia mundial contemporânea, cujos desdobramentos estão na base das crises que o sistema vivencia desde os anos 1990. Referimo-nos ao fato dos capitalistas estarem sempre produzindo excedentes financeiros, os quais necessitam, por força da competição, encontrar saídas para sua absorção na forma de investimentos lucrativos. O problema é que essa expansão ocorre em ritmo composto, a uma taxa aproximada de 3\% ao ano. Então se trata de encontrar aplicação rentável para massas crescentes de recursos, levando investidores a exercitar de forma frenética seus poderes de "destruição criativa" no sentido de sempre alavancar oportunidades de investimento incrementais.

Isso envolve necessariamente os espaços geográficos e, nestes, a urbanização ocupa lugar proeminente. Novos espaços e relações espaciais são produzidos para dar vazão aos imperativos da acumulação de capital. A renda da terra, junto com os juros e o crédito, precisa ser trazida para o centro da análise. Os proprietários do solo e a coalizão de interesses que se forma em torno dos investimentos imobiliários (financistas, incorporadores, políticos, empresários da construção) alargam seu poder de classe e ditam os rumos do crescimento urbano. Ao mesmo tempo, o artificialismo da demanda inchada e da especulação com os preços provoca crises de sobreacumulaçãa, endividamento e um espectro de inadimplências atrás de si. O capitalismo rentista cobra seu preço. O fenômeno do subprime nos EUA é a mais recente e grave dessas manifestações de irracionalismo dos mercados, conduzidas em benefício da plutocracia dirigente. 
Segundo Harvey (2011a, p.30-1) - citando o Relatório do Banco Mundial de 2009 -, a produção total de bens e serviços na economia global foi, naquele ano, de U\$ 56,3 trilhôes, o que, a uma taxa "saudável" para a absorção lucrativa do excedente, significava ter de reinvestir U\$ 3 trilhões em base anualizada. Abaixo desse nível, a economia entra em recessão, estoura a bolha especulativa. Foi o que ocorreu.

Como se materializa essa busca obsessiva pela valorização do capital no espaço urbano, maximizada pela massa volátil de recursos que gira no mercado financeiro e ultrapassa dez vezes o valor da produção global em bens e serviços? É óbvio que o mercado imobiliário é o alvo dessa cobiça, mas novos meios são criados para viabilizar mobilizações maciças de capitais e atender, em bloco, ao apetite dos detentores de riqueza líquida e dos proprietários fundiários: são os chamados grandes projetos urbanos. É possível utilizar tais recursos estabilizadores do próprio capitalismo para construirmos cidades humanizadas, com espaços públicos de qualidade, boas condições habitacionais e de mobilidade, ou o capital imobiliário só cresce produzindo condomínios fechados e favelas? Qual o projeto de sociedade capaz de restituir urbanidades justas, belas e sustentáveis?

O presente artigo desenvolve algumas reflexões sobre esse tema de grande atualidade, priorizando o enfoque político-econômico. Estamos conscientes, porém, de que o assunto requer pesquisas adicionais e acurado monitoramento. $\mathrm{O}$ texto principia com a conceitualização dos grandes projetos urbanos à luz do novo papel das cidades na economia mundial contemporânea, prossegue com considerações sobre a dinâmica imobiliária e a disputa em torno da terra e da renda do solo urbano, e finaliza com a defesa do papel do Estado - em todas as escalas geográficas, mas, sobretudo, do Estado nacional - no ordenamento do território, na fixação de princípios de política regional e na regulação pública do espaço urbano, como um contraponto democrático ao predomínio dos interesses privatistas do mercado imobiliário.

\section{ELITIZAÇÃO E IMPACTOS NAS CIDADES}

Nas últimas décadas, os grandes projetos urbanos (GPUs) vêm sendo disputados por cidades de distintos tamanhos e características como a via preferencial para atrair investidores e potencializar as vantagens competitivas de cada núcleo urbano. Não são propriamente novidades no desenho das grandes urbes, porem na atualidade sua dimensão, conectividade global e íntima vinculação ao processo de reestruturação produtiva em curso os diferenciam. Usualmente consistem na realocação mercantil de glebas bem localizadas, mas degradadas pela obsolescência de seus usos tradicionais. Contudo, também envolvem empreendimentos monumentais, como em cidades no litoral do Golfo Pérsico. "Melhorar a vantagem competitiva urbana é visto como principalmente dependente da melhoria e adaptação do meio-ambiente construído para as estratégias de acumulação das elites-chave de uma cidade e conectando a cidade a economias transnacionais de ponta e redes culturais de elite" (Swyngedouw, 2012, p.53-4). Sua lucratividade advém dos vultosos incrementos no preço da terra advindos dos investimentos imobiliários projetados, e do ciclo especulativo que a perspectiva de altos negócios provoca. Seu vínculo com a globalização financeira é evidente, constituindo canal privilegiado de escoamento para capitais excedentes (muitos deles de origem duvidosa) de todo o mundo.

O espaço constitui, historicamente, elemento integrante dos ciclos de acumulação de capital e válvula de escape de suas crises periódicas, não obstante o fato de também 
expressar os limites e contradiçóes inerentes ao sistema (Smith, 2008, p.177). Pois a economia e as configurações territoriais interatuam reciprocamente. $\mathrm{O}$ poder e o dinheiro se reforçam mutuamente.

Exemplos paradigmáticos de grandes intervençôes urbanas irrompem por todos os lados. A começar por Barcelona, passando por outras cidades espanholas, italianas, norte-americanas e asiáticas. Na China, novas cidades pontuam a paisagem. Algumas delas ainda desertas, numa marcha frenética de "destruição criativa" (Arantes, 2011). E cidades dentro de cidades, como é o caso do grandioso distrito de Pudong, em Xangai. A América Latina participa dessa corrida competitiva interurbana, e Buenos Aires, Santiago, Lima, Cidade do Panamá, Rio de Janeiro, entre muitas outras metrópoles, ostentam grandiosos empreendimentos imobiliários, finalizados ou em execução, e impulsionam projetos urbanísticos de largo alcance.

Por outro lado, grandes projetos urbanos absorvem somas crescentes de recursos financeiros e, não raro, se veem em dificuldades na ocorrência de crises. É o caso, por exemplo, de iniciativas colossais em Dubai, como as World Islands - cerca de 300 ilhas artificiais cujos preços de venda situam-se entre 50 e 250 milhóes cada -, que, com o refluxo do mercado imobiliário, acumulam dívida superior a 18,5 bilhóes. Fenômeno semelhante ocorre com o megalômano projeto Pearl Qatar, em Doha. As somas envolvidas são fabulosas, e nos dão uma pálida ideia de como os GPUs contribuem para o escoamento do excedente de capitais - e provocam subsequentemente as crises. Em Boston, EUA, o projeto já concluído do Big Dig - uma completa requalificação de área possibilitada pela demolição de uma extensa via elevada, a construção de um túnel e a abertura de vastas glebas para empreendimentos imobiliários - consumiu, depois de inúmeras e controvertidas majoraçôes orçamentárias, US\$ 22 bilhôes, dez vezes mais que seu custeio original. Lembremos que o valor total dos projetos da Copa 2014 no Brasil deve consumir em torno de R $\$ 85$ bilhóes! E nós já tivemos um mau exemplo de desperdício de recursos com os Jogos Pan-Americanos no Rio em 2011. Aliás, grandes eventos são usados como catalisadores de investimentos e reformas urbanas e, a par de seus discutíveis resultados sociais - pois o alvo são grandes negócios e o benefício apropriado pela parcela mais rica da população -, muitas vezes terminam com saldo no vermelho, com um legado de "elefantes brancos" e dívidas.

Em outra publicação recente, Harvey (2011b) faz uma releitura de Henri Lefebvre e define que o direito à cidade é estabelecer um poder radical sobre o processo de urbanização, o que depende da mobilização social do excedente. Aponta ainda que os grandes projetos urbanos são historicamente estabilizadores do capital, citando os exemplos de Haussmann, na Paris do século XIX, de Robert Moses em Nova Iorque, na segunda metade do século XX, e, atualmente, no boom imobiliário chinês. Acrescentaríamos, nessa relação, o exemplo atual de Dubai, que constitui uma amostra prática da postulação de Harvey. Surgida com o excedente petrolífero, a criação de uma nova centralidade terciária global as margens do Golfo Pérsico repete o mesmo paradigma urbanístico (equivocado e insustentável) do século XX, baseado no uso intensivo do automóvel, na dispersão, na fragmentação urbana e desperdício de asfalto e concreto, onde até os pontos de ônibus têm ar condicionado. Criaram terra, pois tinham pouca, e ligaram o oriente e o ocidente pelo hub aéreo de Dubai/Abu Dhabi. Alem disso, construíram milhões de metros quadrados ainda vazios, mas em processo de ocupação, reproduzindo o capital excedente global. Em síntese, como já notamos, do ponto de vista urbanístico tais intervençôes reproduzem, em grande parte, características altamente problemáticas da concepção modernista clássi- 
ca, como a prioridade rodoviarista (o automóvel), a cidade difusa e o funcionalismo, isto é, a especialização de usos por zonas territoriais pré-definidas.

Sem buscar descrever empiricamente exemplos de projetos urbanos, que não é o propósito deste artigo, entendemos que alguns deles, principalmente na Europa, apontam elementos de inclusão promovendo a provisão de habitação social, de espaços públicos de qualidade ou ainda construindo alternativas de trabalho e renda. Este é o caso de Paris Rive Gauche, no qual o governo socialista de Delanoé ampliou o número de habitaçóes populares de aluguel de 5000 para 7000 unidades e onde um antigo moinho foi tomado por movimentos culturais, constituindo um espaço de negociação (Somekh, 2010). Ou ainda na experiência do Norte de Milão, onde a prefeitura de Sesto San Giovanni, aliado a lideranças sindicais, negociou a reocupação de plantas industriais tombadas com um novo tecido produtivo, composto de micro e pequenas empresas dirigidas por antigos trabalhadores do setor siderúrgico, desmontado na Europa. A iniciativa contou com recursos da União Europeia num programa de capacitação para o empreendedorismo (Somekh, 2006, p. 265).

Mesmo na América Latina o controverso projeto de Puerto Madero, em Buenos Aires, gestado desde 1900 (Abascal e Zylberstjain, 2010), embora produzindo um espaço "global", também proporcionou a recuperação do Patrimônio Histórico, constituído pelos antigos armazéns, bem como a implementação de espaços públicos generosos e inclusivos. Como também o Transmilênio de Bogotá, versão atualizada e sustentável dos corredores brasileiros, que reduziu consideravelmente o tempo de deslocamento dos trabalhadores (Abramo, 2008), mostra que com um bom projeto é possível atender demandas sociais.

O caso do concurso para escritórios de Arquitetura para a "Grand Paris", com o objetivo de desenhar a Metrópole pós-Kyoto, realizado em 2008, aponta dois tipos de projetos metropolitanos. Um voltado para a globalização e outro para a requalificação dos espaços e serviços urbanos (Somekh, 2010). Isto se materializa nos recentes debates sobre o novo traçado do metrô parisiense: os interesses fundiários atendidos e a constituição de uma nova centralidade global, defendida pelo governo nacional (Grand 8), ou a melhoria dos serviços urbanos (Arc Express), reivindicada pelo governo regional de Ile de France.

Essa dualidade não é nova. Nos anos 1990 a pesquisa que avaliou os projetos urbanos na Europa (Morandi e Pucci, 1998) detectava duas famílias de projetos: uma voltada para as necessidades do mercado e da globalização e outra voltada a recuperar funçóes obsoletas das cidades. Em 1994, segundo Arantes (2012), o urbanista Dieter Frick estabelecia dois cenários compostos para Berlim: um deles, equipar a "global city", procurando atrair multinacionais, e outro, buscar uma cidade "com fisionomia humana". Arantes afirma que, passados muitos anos, a fusão de modelos não aconteceu e pelos seus prognósticos não acontecerá. Segundo a autora, Berlim e Barcelona desencadearam operaçóes do Cultural World e dois grandes eventos que alavancaram sua "renovação urbana".

Ainda segundo Arantes, os Jogos Olímpicos no Brasil também estão suscitando intervenções "no front cultural", já presentes na época dos Jogos Panamericanos do Rio de Janeiro que se constituíram num legado-desastre (Egler e Oliveira, 2010). São Paulo, com o projeto "Nova Luz" e com milhares de hectares definidos como área de Projeto Urbano pela prefeitura, não tem um modelo de transformação contemporânea da cidade (Somekh, 2011). Um modelo a ser desenvolvido deve atualizar a cidade, mas deve reparar seu passivo social, buscando novas alternativas produtivas geradoras de trabalho.

Por certo, a geração de valor, na moderna economia globalizada, não se limita apenas às fábricas ou às unidades produtoras de serviços. Com a terceirização crescente dos ser- 
viços, seja no circuito superior da economia, ou no inferior, a cidade se transforma cada vez mais em espaço produtivo. Isto no aspecto econômico, como também no cultural, estético e simbólico, dimensões nas quais o presente modelo de acumulação de capital está profundamente imbricado. As relações sociais evidenciam maior individualização e diversificação. Dissemina-se a mercantilização. A crise do fordismo urbano implicou no predomínio do mercado como mecanismo de coordenação das decisōes de uso do solo, aspecto este característico da cidade neoliberal (Abramo, 2012, p.36). O que converte o espaço urbano propriamente dito em objeto de inversões diversas, maximizando a importância das externalidades de toda ordem, associadas a processos não raro massivos de deslocamento de atividades e pessoas (Sassen, 2010).

Contudo, a ocorrência do conjunto de tais fenômenos de valorização da terra não está limitada às chamadas cidades globais - ou seja, poucas dezenas de centros urbanos dispersos pelo mundo que preenchem requisitos distintivos não muito claros, cujas máximas expressóes seriam Nova Iorque, Londres e Tóquio (Sassen, 2001) -, pois constatamos que os mesmos atributos se verificam, em maior ou menor grau, em quase todas as principais cidades do mundo conectadas aos fluxos econômicos hegemônicos, bem como em centros regionais de segunda ordem, com esferas de comando mais restritas. Recentes sondagens apontam 400 cidades médias (de até 2 milhões de habitantes) em mercados emergentes como catalisadoras de $40 \%$ do crescimento econômico mundial nos próximos quinze anos (McKinsey Quarterly, 2011). Seja como for, as correlaçôes entre o novo quadro econômico e suas manifestaçóes espaciais urbanas permitem detectar precisamente os esboços de uma realidade citadina bastante diferenciada - de alcance regional, macrometropolitano - frente aos parâmetros anteriormente consagrados da morfologia urbana, em especial aqueles típicos do fordismo (Gaspar, 2011a; 2011b). A própria ONU reconhece a primazia dos grandes aglomerados urbanos na economia global de nossa época, resultado dos emergentes vínculos entre o crescimento das cidades e os novos parâmetros da atividade econômica, organizada em sistemas (clusters) regionais (UN-Habitat, 2010, p.8-10).

Atualmente, "O dado organizacional é o espaço de fluxos estruturadores do território e não mais, como na fase anterior, espaços onde os fluxos de matéria desenhavam a ossatura do sistema urbano" (Santos, 2008, p.103).

Os grandes projetos urbanos se encaixam nessa nova realidade das cidades, pelo potencial de acumulação privada que ostentam, agregando múltiplos interesses financeiros e imobiliários de poderosos grupos internacionalizados. De um ponto de vista crítico, os GPUs acabam quase sempre associados à valorização do solo, concomitante elevação do preço dos imóveis, desalojamento de populaçóes e empresas incapacitadas de pagar pelo preço da terra, elitização dos espaços melhor localizados (acessibilidade), segregação socioespacial e espraiamento (suburbanização) do crescimento urbano - ocasionando congestionamentos, prejuízos ambientais e acréscimo de custos, decorrente da expansão territorial dos serviços públicos. O Estado, em quaisquer dos seus níveis, é muitas vezes conivente com esses processos, já que participa economicamente dos GPUs na condição de regulador, prestamista e investidor direto, embora na qualidade de avalista dos lucros privados. É possível modificar essa conduta mediante novas práticas democráticas?

Tais resultados derivam diretamente das características da economia mundial contemporânea e da captura dos interesses públicos pela lógica financeira. A centralização econômica produzida e alimentada pelo mercado requer uma determinada centralização espacial do mesmo capital (Smith, 2008, p.164). Aspectos esses típicos de como as coisas funcionam no capitalismo atual. Como a orientação do progresso tecnológico possui 
íntima conexão com o sistema de dominação social, cuja principal função é assegurar a apropriação do excedente, a concentração de recursos e de poder nos aglomerados metropolitanos globais expressam geograficamente a correlação espacial do poder econômico concentrado, próprio do mundo corporativo (Sassen, 2007, p.138-9).

Krugman (1991, p.5 e p.98) afirma com razão que a mais notável particularidade da geografia da atividade econômica é sua concentração no espaço, devido aos custos de transação e as economias de escala. Contudo, deve-se completar que esse processo se relaciona intimamente com a expansão do capitalismo. De fato, o espaço urbano é capitalizado como espaço de produção - enquanto, em outras épocas, a organização do mercado de trocas, motivações religiosas ou de defesa justificavam o fortalecimento da cidade.

Muitos acreditaram que a diminuição dos custos de transporte oriunda da aplicação das modernas tecnologias de informação e comunicação produziria maior flexibilidade na opção locacional, assim permitindo o desenvolvimento da periferia do sistema. $\mathrm{Na}$ verdade o oposto sucedeu: o progressivo desaparecimento dos tradicionais fatores de localização levou a que novas condições prevalecessem, conduzindo as firmas a se congregar em regiōes que não oferecem vantagens comparativas naturais. Em outras palavras, "embora as firmas sejam livres para optar pela melhor localização, elas gradualmente perdem sua maleabilidade uma vez que os efeitos das novas forças de aglomeração associadas aos retornos crescentes entram em jogo" (Combes et al., 2008, p.247). O crescimento dos espaços eletrônicos não está se direcionando para a dissolução das cidades: "Não estamos inaugurando um mundo pós-urbano, muito pelo contrário, estamos vivendo o reforço do urbano" (Lemos, 2005, p.29). A apropriação do excedente e a estabilização de estruturas desiguais de poder dependem hoje, fundamentalmente, do controle da informação e do condicionamento da criatividade, atividades profundamente urbanas, localizadas em centros direcionais do mundo e influenciadas pela concentração de recursos própria das economias de aglomeração. É nesse contexto que os grandes projetos urbanos se inscrevem crescentemente na paisagem metropolitana em todo o planeta.

\section{VALOR DO SOLO E ESPECULAÇÃO}

O desenvolvimento do mercado imobiliário revela uma das características distintivas dos grandes centros urbanos na atualidade. Constitui, ademais, verdadeira pedra de toque a medir a viabilidade e o alcance dos objetivos previstos nos grandes projetos urbanos. Por isso, justifica-se a atenção nos processos de formação da renda do solo, sua apropriação e a dinâmica do mercado imobiliário. Padróes internacionais convergentes de estilos arquitetônicos e atração de capital estrangeiro representam alguns de seus aspectos principais. Tais elementos ganham corpo no contexto de

uma mudança de longo prazo na natureza da propriedade do solo, do que poderíamos chamar 'propriedade industrial do solo' (quando a posse da terra é condição para outra produção) para a 'propriedade financeira do solo', quando a propriedade da terra é em si mesma um meio de extrair renda (Massey, 2007, p.48).

Os grandes projetos de renovação urbana materializam, como tem sido enfatizado no presente estudo, importantes premissas do urbanismo contemporâneo. "Os grandes projetos desse tipo expressam uma nova paisagem física e social da centralidade urbana, 
no contexto da globalização" (Cuenya, 2011, p.186). O privilégio da lógica mercantil, a privatização dos usos e a participação do setor público como suporte da arquitetura do plano e fiador da engenharia financeira figuram entre eles. Claro que existem flagrantes diferenças de estilo e concepção nos projetos monumentais de requalificação urbana que muitas cidades do mundo executam. Porém, no geral, a rentabilidade do uso do solo e a captura privada de mais-valias em setores particulares da cidade traduzem a norma, expressam sua atratividade.

Um corolário determinante da hegemonia dos mercados financeiros nas mais importantes cidades do planeta se dá pela via da compra e venda de imóveis de luxo. A construção de torres de escritórios de empresas de serviços de ponta, sedes administrativas de corporações transnacionais, parques temáticos, complexos aeroportuários, hotéis de poderosas cadeias internacionais, shopping centers, equipamentos culturais de alto nível, edifícios residenciais de alto padrão e condomínios fechados justificam vultosas inversões. Grandes projetos urbanos, com dinheiro público, lhes abrem terreno. Esse comportamento, aliado ao movimento dos proprietários de terra, eleva às alturas os valores do solo urbano e a especulação imobiliária, desloca populações inteiras de renda mediana ou baixa de bairros tradicionais ("gentrificação") e agrava o fenômeno da dispersão metropolitana. Cidades de distintos graus de desenvolvimento socioeconômico em qualquer continente vivem essa realidade, resultado do privilégio ao rodoviarismo e aos veículos particulares que evidenciam gestão diferenciada no controle da acessibilidade. Em algumas os contrastes são mais agudos - como a favelização nas metrópoles latinoamericanas. Os condomínios fechados, que afetam distintos grupos sociais (os ricos em primeiro lugar, mas não somente eles), também constituem fenômeno generalizado de segregação, hostilidade e exclusão. A planificação metropolitana incorpora dinâmicas reticulares (splintering urbanism) (Mattos, 2008).

A elevação dos preços do solo urbano é a expressão paradigmática de uma vantagem privada e unilateral, que emerge de um processo coletivo, a urbanização. No entanto, tais incrementos do valor da terra e dos imóveis (as mais-valias urbanas), sem uma intervenção por parte do setor público para sua recuperação, total ou parcial, são apropriados exclusivamente pelos proprietários da terra e dos imóveis beneficiados pela valorização de determinado setor da cidade. $\mathrm{O}$ solo, o subsolo e o espaço aéreo urbano são avaliados pelos seus valores de troca. A função social e a propriedade particular do solo assumem assim, via de regra, estatutos antagônicos.

O solo não possui custo de produção. É o uso do território, e não o território em si mesmo, que faz dele objeto de desejo. Por conseguinte, seu preço se forma exclusivamente como função da demanda. Em virtude de características únicas de localização que cada terreno tem com respeito ao restante das glebas da cidade, seu proprietário adquire condições únicas - originadas da escassez - que lhe permite exigir um preço de tipo monopólico (Doebele, 1997).

O rentismo caracteriza boa parte da riqueza atual, pois a propriedade patrimonial que lhe serve de base - "cria direitos a rendas sob a forma de alugueis, de rendas do solo (urbano e rural) e de fluxo de rendas relacionadas às aplicações na Bolsa” (Chesnais, 2005, p.50). De sorte que as vantagens e desvantagens do espaço construído geram conflitos sociais e produzem a apropriação desigual das localizaçōes da cidade. É a manifestação mais cabal do poder na esfera intraurbana (Villaça, 2001). Daí resulta a segregação espacial que visa, principalmente, o controle das acessibilidades (os tempos de deslocamento) por parte dos segmentos de alta renda. 
Reconhecemos que o preço da terra urbana se forma não somente pela concentração dos melhores terrenos nas mãos dos empresários imobiliários e a consequente elevação da renda do solo: este sistema de renda da terra atua, sim, ao menos no nível elementar de determinação dos valores do solo. Contudo, um complexo jogo de convenções de mercado configura, ao final do trajeto, as decisões de localização e a produção residencial. Nesse processo, os preços se estabelecem com base em expectativas de mercado futuro - a formação de novas externalidades de vizinhança. Sucessivos encadeamentos de decisóes de compradores e vendedores de imóveis, assim como sua sanção monetária (o crédito), permitem ou não a materialização dos projetos de edificação imobiliária, desvalorizando o estoque habitacional existente e valorizando as áreas hospedeiras dos projetos inovadores. Portanto, a incerteza constitui a marca registrada desse mercado, sobretudo especulativo (Abramo, 2007).

Nesse sentido, existe um fenômeno real que reflete economias externas criadas para o conjunto do sistema especialmente devido às inversões públicas, e existe uma valorização artificial de base especulativa que pode ir longe quando é grande a abundância de recursos financeiros (liquidez). Os GPUs jogam com a alternância de elementos objetivos e subjetivos presentes no mercado de bens-raízes. A financeirização da economia, em particular, eleva a especulação a níveis inéditos, ao manter em forma líquida quantidades de recursos que ultrapassam em muito o produto interno bruto dos principais países e o volume do comercio global, como vimos. As crises financeiras internacionais recentes aquela iniciada em algumas das principais metrópoles asiáticas, em meados dos noventa, e a desencadeada pela quebra do mercado hipotecário americano, em 2008 - originaram-se de intensos movimentos de preços no mercado imobiliário urbano, culminando com a explosão da bolha especulativa e seu imediato contágio universal.

Harvey aponta, uma vez mais, o significado da produção do espaço em geral e da urbanização em particular como grandes negócios no capitalismo atual, bem como identifica os agentes desse processo:

O poder dos proprietários de terras e recursos tem sido muito subestimado, assim como o papel dos valores dos ativos e rendas das terras e recursos na circulação global do capital. Essa arena de atividade movimenta algo como $40 \%$ da atividade econômica em muitos dos países capitalistas avançados. Não surpreende então que as infraestruturas urbanas sejam um componente fundamental nos pacotes de estímulo dos governos para levantar suas economias em ruínas. Alem disso, é vital vê-lo como um poder ativo e não passivo, pois é justamente por meio da realização de novas geografias que os proprietários (em aliança com desenvolvedores, interesses da construção e, claro, financiadores onipresentes) avançam a sua posição de classe, além de trazer soluçóes-chave para o problema da absorção do excedente de capital (Harvey, 2011a, p.149).

As decisões governamentais concernentes à regulamentação do uso e ocupação do solo e as políticas públicas delas derivadas adquirem caráter potencialmente conflitivo, pois afetam fraçôes do capital comprometidas com a apropriação da renda da terra urbana. A natureza eminentemente mercantil do ambiente construído e a consequente segregação social em seu uso reforçam a importância histórica do controle da terra como instrumento de poder. As cidades latinoamericanas ilustram esse ponto exaustivamente. Intervenções econômicas e políticas do Estado alteram o valor de troca do espaço construído, na medida em que induzem investimentos ou definem vantagens de localização. 
Assim sendo, iniciativas do governo nesse campo sempre implicam concentração ou distribuição de recursos.

No entanto, acreditamos ser possível contrapor, ao menos em parte, uma lógica alternativa e democrática a essa perspectiva hegemônica, compatibilizando recursos e procedimentos em prol de uma cidade mais humana.

\section{ESTADO, PLANEJAMENTO E DEMOCRACIA}

A concepção de Estado com a qual trabalhamos não equipara o aparelho estatal ao "comitê de representantes da burguesia". Se a burguesia detem a supremacia, antes, o Estado é produto e construtor de consensos e coalizóes, resultados da tensão social entre classes e frações de classe. Caixa de ressonância do conflito social, o Estado cristaliza, na forma de ações e políticas públicas, uma determinada correlação de forças políticas, sempre transitória. As hegemonias são assim construídas e reconstruídas. Os consensos transitórios repercutem no espaço, numa dialética de recíproca influência e permanente interação. Se o espaço é relacional, fruto de práticas e fluxos sociais, os lugares constituem articulações específicas, no interior de amplas geometrias de poder (Massey, 2007, p.167), dentro das quais compete ao Estado o papel decisivo (Gaspar, 2008).

Um documento do Programa das Nações Unidas para o Desenvolvimento (PNUD) expressa bem a noção de que não existe Estado neutro:

(...) O Estado é um espaço de condensação complexa e de mediação de forças sociais. Na verdade, a visão neutra é uma maneira de argumentar em favor de um tipo de Estado que, por meio de suas políticas e, certamente, de suas omissóes, é um ativo reprodutor de desigualdade e um grande obstáculo à expansão de direitos civis e sociais (PNUD, 2004, p.66).

Se a determinação hegemônica dos processos espaciais urbanos atuais cabe inegavelmente ao mercado imobiliário, condicionado à financeirização que preside o capitalismo globalizado (Fix, 2011), a realidade é dinâmica e comporta infinitas combinações no jogo de poder. Espaço é multiplicidade, é "a esfera da contínua produção e reconfiguração da heterogeneidade em todas as suas formas - diversidade, subordinação, interesses conflituosos" (Massey, 2005, p.61). E conclui a autora: ao espaço relacional deve corresponder uma política relacional, radicalmente democrática.

Mas o Estado, assim como todas as dimensões da vida humana, mudou muito com as transformações da economia global nos últimos trinta anos. Divide sua jurisdição com um conjunto de outras instituições, algumas ainda em processo de formação. Não obstante esse reconhecimento, é possível afirmar que o novo papel do Estado enquanto empreendedor possui dois componentes:

primeiramente, sua posição como agente central o implica na posição crucial de prover uma visão de futuro num período de transformação. Em segundo lugar, seu papel como construtor de instituiçóes lhe permite dar realidade institucional a essa visão, assim como à emergente estrutura de coordenação (Chang, 2003, p.69).

Essa insubstituível função da esfera pública em nossa era histórica concerne a todos os níveis de poder, do local ao global. 
Os interesses hegemônicos do capital compreendem a importância de ter o Estado jogando em seu favor. Tanto é assim que o manejo, por tais grupos, do aparato estatal pós-keynesiano reestruturado está direcionado, sobretudo, a fornecer as pré-condições territoriais e bens coletivos essenciais para a consolidação empresarial em outras escalas (supra ou subnacionais); isto é, os fatores de produção imóveis destinados a gerar as externalidades associadas ao momento de fixação territorial do capital no interior das grandes cidades-regiōes (Brenner, 2006, p.263-4).

A experiência internacional aponta a presença do Estado como principal interventor na formulação e implementação dos projetos urbanos, que justapõe a intervenção pública e a intervenção privada. E aqui governos locais e regionais progressistas podem fazer a diferença. Mesmo nos Estados Unidos, onde o setor privado predomina, os grandes investimentos públicos, principalmente em infraestrutura de transportes e criação de espaços públicos e equipamentos culturais, é que efetivamente viabilizam os GPUs. Outra lição é a de que soluções efetivas para os problemas urbanos dependem hoje do envolvimento dos atores locais, da sociedade civil e de diversas esferas governamentais, na busca de novas formas de gestão e da capacidade de governança. Pode-se observar que os instrumentos de planejamento tradicionais, muito centralizados, que regulam o uso da terra e o desenvolvimento urbano - como no Brasil - tornaram-se obsoletos (Leite e Somekh, 2008).

Em face da crise econômica, da reestruturação produtiva e da redefinição do papel do Estado, destaca-se cada vez mais a necessidade de formas de ação concebidas e executadas em nível local, com o objetivo de promover o desenvolvimento econômico. Os elementos básicos do que Harvey denomina "empreendedorismo local" envolvem não apenas o desenvolvimento de parcerias entre o poder público e o setor privado, mas a capacidade mais geral de articulação, por parte dos atores e forças sociais. Partindo do princípio de que o poder de ordenar o espaço deriva de um complexo conjunto de forças, mobilizadas por diversos agentes, o governo local deve coordenar uma ampla gama de forças sociais, exercitando a governança urbana.

Muitas experiências recentes de articulação entre os setores público e privado apontam para uma possível reorientação do poder local, com vistas à inserção de questôes relacionadas ao desenvolvimento econômico e social na agenda política. Todavia, o recurso à ação pontual dos governos locais coloca o risco do acirramento dos desequilíbrios regionais e internacionais, da mesma forma que a disputa pelos investimentos no quadro do planejamento estratégico - na medida em que algumas localidades estão mais bem equipadas do que outras na luta autônoma pelo desenvolvimento. Para evitar os efeitos deletérios dessa disputa, das guerras fiscais suicidas à exacerbação das diferenças, aumentando o abismo entre regiōes privilegiadas e esquecidas, é preciso contar com instâncias regulatórias nas diversas esferas - local, regional, nacional e mesmo internacional.

Embora somente o futuro possa dizer se as iniciativas de desenvolvimento local terão fôlego suficiente para superar problemas existentes e consolidar a reconversão industrial num processo de desenvolvimento sustentável, alguns limites já podem ser assinalados. Em primeiro lugar, trata-se de um esforço que apresenta autonomia relativa e que, consequentemente, não pode prescindir de políticas nacionais, estaduais e regionais de desenvolvimento. Outros limites podem resultar do individualismo das tradicionais culturas municipalista e empresarial, da prevalência de interesses pontuais e casuísticos na esfera local, e da descontinuidade político-administrativa, que acarretam o risco de desestruturar esforços coletivos de longo prazo (Somekh e Campos, 2001). 


\section{CONSIDERAÇÕES FINAIS}

A par das consequências negativas brevemente apontadas acima, os GPUs apresentam diversas positividades que devem ser exploradas, respeitando-se projetos e ambientes institucionais adequados. Políticas públicas, aparato legal, mecanismos econômico-financeiros apropriados, bem como a qualidade da intervenção urbanística desenhada, têm o condão de potencializar os efeitos socialmente relevantes dos projetos de reestruturação territorial, disseminando seus reflexos no conjunto do ambiente construído. É preciso salientar, contudo, que as soluções adotadas e o equilíbrio das diversas tendências em disputa estão mais no campo propriamente político que na esfera do conhecimento técnico.

A requalificação de áreas pode, em si, ser um fenômeno extremamente favorável, pois afeta grandes espaços, quando não cidades e regiões inteiras. Contribui para melhorar a qualidade de vida, favorecer linhas de desenvolvimento sustentável, atualizar a infraestrutura, criar empregos ou alternativas de trabalho, entre outras virtudes. $\mathrm{O}$ instrumento principal de financiamento dessas operaçóes urbanísticas costuma ser a valorização da terra, mas aqui mora o perigo: a captura exclusivamente privada da mais-valia fundiária, quando mecanismos majoritariamente sociais a provocaram. A privatização desses benefícios leva a distorçôes que em última análise inviabilizam a sustentabilidade social do projeto e as externalidades positivas que ele pode gerar em prol do desenvolvimento urbano e regional integral. Uma maneira de evitar semelhantes consequências é ter uma participação mais efetiva do governo nacional na regulação e operacionalização de programas e políticas de fomento urbano e regional. Isso é ainda mais válido em países de dimensão continental como o Brasil. A preocupação com a natureza do projeto também é fundamental: a regulação pública precisa garantir a mistura de usos, a inclusão social, o provimento habitacional, os espaços públicos, a qualidade ambiental, a recuperação e redistribuição social da valorização do solo, além da integração com os planos mais abrangentes de conteúdo macrourbano, metropolitano e regional. Essas dimensóes - apesar do avanço que tivemos no âmbito intraurbano com o Estatuto da Terra e o Ministério das Cidades - são raramente encontradas no Brasil.

Se as economias de aglomeração continuam a ser decisivo fator de localização, criando ambientes inovadores e competitivos, a resolução de seus gargalos implica desenvolver planos e políticas capazes de articular outras escalas territoriais, principalmente nacionais. Ademais, reconhecer a primazia urbana implica a admissão da irreversibilidade de tal fenômeno, haja vista de que as cidades representam a única saída para abrigar a crescente população mundial e uma hipotética alternativa rural intensiva ocasionaria um desastre ecológico sem precedentes. Faz-se imperativo forjar redes urbanas mais sustentáveis, atenuando os prejuízos advindos da ocupação desordenada, massivamente concentrada. $\mathrm{O}$ que conduz a questionar a forma como a humanidade utiliza o planeta, explora seus recursos e se relaciona com seus iguais.

Desse modo, os grandes projetos urbanos exigem, para sua plena inserção na vida da cidade, estar incluídos em planos de mais largo alcance, sob o prisma econômico e territorial. Para tanto, são requeridas mudanças estruturais, abordagens integradas, agregando múltiplas escalas geográficas, com o intuito de se lograr políticas de desenvolvimento efetivas e impactos positivos no âmbito social e ambiental.

Em suma, os elementos recorrentes apontados pela experiência internacional no manejo dos grandes projetos urbanos incluem uma unidade de gestão centralizada, a importância nuclear da questão dos transportes gerando as chamadas novas centralidades, 
Nadia Somekh é arquiteta, Mestre e Doutora pela FAU-USP. Professora Titular da Faculdade de Arquitetura e Urbanismo da Universidade Presbiteriana Mackenzie. E-mail: nadiasom@terra. com.br

Ricardo Carlos Gaspar é sociólogo graduado pela FESP-SP, Mestre e Doutor pela PUC-SP. Professor Doutor do Departamento de Economia da FEA/PUC-SP. E-mail: ricgaspar@gmail.com

Artigo recebido em dezembro de 2012 e aprovado para publicação em fevereiro de 2013. a existência de âncoras culturais, bem como de ambientes ou setores voltados para a inovação tecnológica, alem do investimento na ampliação da qualidade dos espaços públicos oferecidos à população. Cabe a sociedade organizada articular ações que contraponham o interesse público à lógica estritamente privada, do mercado imobiliário incontrolado. Um mundo mais humano e digno de se viver requer não apenas alterações profundas na estrutura econômica global, mas na maneira como o espaço construído, nas esferas local e regional, é organizado e apropriado, como David Harvey corretamente nos adverte.

\section{REFERÊNCIAS BIBLIOGRÁFICAS}

ABASCAL, E. H. S.; ZYLBERSTJAIN, B. E. "Porto Madero, Buenos Aires: formação e implantação do porto - genealogia de um projeto insígnia”. In: CAMPOS NETO, C. M. et. al. A cidade iberoamericana: história, cultura e urbanismo - passagens do ideário urbanístico entre Buenos Aires, Rio de Janeiro e São Paulo. Relatório Técnico de Pesquisa. São Paulo, Mackpesquisa (mimeo), 2010.

ABRAMO, P. A cidade caleidoscópica: coordenação espacial e convenção urbana: uma perspectiva heterodoxa para a economia urbana. Rio de Janeiro: Bertrand Brasil, 2007.

"A experiência latinoamericana de projetos urbanos". Apresentação no Segundo Colóquio Internacional: Projetos Urbanos, Reconversão e Inclusão Social. São Paulo, Universidade Mackenzie, setembro de 2008.

"La ciudad com-fusa: mercado y producción de la estructura urbana en las grandes metrópolis latinoamericanas". Revista EURE vol. 38 no 114. Santiago, PUC-Chile, 2012.

ARANTES, O. Chai-na. São Paulo, EDUSP, 2011.

. Berlim e Barcelona: duas imagens estratégicas. São Paulo, Annablume,

2012.

BRENNER, N. "Global cities, "glocal" states: global city formation and state territorial restructuring in contemporary Europe". In: BRENNER, N. and KEIL, R. (eds.). The global cities reader. New York, Routledge, 2006.

CHANG, H. J. Globalisation, economic development and the role of the State. London and New York, Zed Books; Penang, Third World Network, 2003.

CHESNAIS, F. "O capital portador de juros: acumulação, internacionalização, efeitos econômicos e políticos". In: CHESNAIS, F. (org.). A finança mundializada: raízes sociais e políticas, configuração, consequências. São Paulo: Boitempo, 2005.

COMBES, P. P.; MAYER, T.; THISSE, J. F. Economic geography: the integration of regions and nations. Princeton and Oxford, Princeton University Press, 2008.

CUENYA, B. "Grandes proyectos y sus impactos en la centralidad urbana". Cadernos Metrópole v. 13 n. 25. São Paulo, EDUC, 2011.

DOEBELE, W. "Land use and taxation issues in developing countries". In: BROWN, H. J. (ed.). Land use and taxation: applying the insights of Henry George. Cambridge/MA, Lincoln Institute of Land Policy, 1997.

EGLER, T. T. C.; OLIVEIRA, F. M. “Jogo no Rio”. Revista Brasileira de Estudos Urbanos e Regionais v. 12 no 2. Associação Nacional de Pós-Graduação e Pesquisa em Planejamento Urbano e Regional, novembro de 2010.

FIX, M. Financeirização e transformações recentes no circuito do capital imobiliário no Brasil. Tese de Doutoramento. Campinas, Instituto de Economia, Unicamp, 2011. 
GASPAR, R. C. (2008). "Estado, instituciones y desarrollo urbano". In: MONTÚFAR, M. C. (Coord.). Lo urbano en su complejidad: una lectura desde América Latina. Quito, FLACSO; Ministerio de Cultura del Ecuador.

Las ciudades en la globalización: economía, espacio y poder. Saarbrücken, LAP LAMBERT Academic Publishing \& Co, 2011a.

. "A economia política da urbanização contemporânea". Cadernos Metrópole vol. 13, 2011 (no 25). São Paulo, EDUC, 2001b.

HARVEY, D. O enigma do capital e as crises do capitalismo. São Paulo: Boitempo, 2011 a. . Le capitalisme contre le droit a la ville: neoliberalisme, urbanisation et résistence. Paris, Ed. Amsterdam, 2011b.

KRUGMAN, P. Geography and trade. Cambridge/MA, MIT Press, 1991.

LEITE, C.; SOMEKH, N. São Paulo: implementando a mudança urbana. Texto apresentado no Urban Age: South America Conference, São Paulo, dezembro de 2008. http:// vitruvius.com.br/revistas/read/minhacidade/09.105/1855.

LEMOS, A. "Cidade ciborgue: a cidade na cibercultura". In: LEMOS, A. (Org.). Cibercidade II: cibercidade, a cidade na sociedade da informação. Rio de Janeiro, E-papers, 2005. MASSEY, D. For space. London, Sage Publications, 2005. World city. Cambridge, UK, Polity Press, 2007.

MATTOS, C. A. "Globalización, negocios inmobiliarios y mercantilización del desarrollo urbano”. In: MONTÚFAR, M. C. (Coord.). Lo urbano en su complejidad: una lectura desde America Latina. Quito, FLACSO Ecuador; Ministerio de Cultura del Ecuador, 2008.

MCKINSEY QUARTERLY (2011). The world's new growth frontier: midsize cities in emerging markets. <www.mckinseyquarterly.com>, mar/2011.

MORANDI, C.; PUCCI, P. Prodotti notevoli. Milano, Francoangeli, 1998.

PNUD. A democracia na América Latina: rumo a uma democracia de cidadãs e cidadãos. Programa das Naçôes Unidas para o Desenvolvimento. Santana de Parnaíba/SP, L, M \& X, 2004.

SANTOS, M. A urbanização brasileira. São Paulo, EDUSP, 2008.

SASSEN, S. The global city: London, New York, Tokyo. $2^{\text {nd }}$ edition. New Jersey, Princeton University Press, 2001. . Una sociología de la globalización. Buenos Aires: Katz Editores, 2007. "Cities in today's global age". In: UNESCO. World social science report 2010: knowledge divides. Paris, UNESCO; International Social Sciences Council, 2010. SMITH, N. Uneven development: nature, capital, and the production of space. $3^{\text {rd }}$ edition. Athens/GE, University of Georgia Press, 2008.

SOMEKH, N.; CAMPOS, C. M. Desenvolvimento local e projetos urbanos. Associação Nacional de Pós-Graduação e Pesquisa em Planejamento Urbano e Regional. Rio de Janeiro, IX Encontro Nacional da ANPUR, 2001.

"Projetos urbanos / utopias realizáveis: o caso do centro de São Paulo". In:

GASPAR, R.; AKERMAN, M.; GARIBE, R. (Orgs.). Espaço urbano e inclusão social: a gestão pública na cidade de São Paulo 2001-2004. São Paulo, Ed. Perseu Abramo, 2006.

Arquitetura e metrópole: projetos urbanos da "Grand Paris". Anais do Simpósio Temático: Projetos Urbanos e a Reinvenção do Espaço-Mundo na Cidade Contemporânea. Rio de Janeiro, I Encontro Nacional da Associação Nacional de Arquitetos (ENAPARQ), 2010.

. Um Projeto Urbano para São Paulo? In: CAMPAGNER, L.; CALDANA, V. (orgs.) Projetos Urbanos em São Paulo. São Paulo, Livre Expressão, 2011. 
SWYNGEDOUW, E. A cidade pós-política. @metropolis: revista eletrônica de estudos urbanos e regionais, $n^{\circ}$ 08, ano 3, 2012.

VILLAÇA, F. Espaço intra-urbano no Brasil. São Paulo, Studio Nobel; FAPESP; Lincoln Institute of Land Policy, 2001.

UN-HABITAT. State of the world's cities 2010/2011: bridging the urban divide. Nairobi, UN-Habitat; London, Earthscan, 2010.

A B S T R A C T This article offers some reflections on the relationship among large urban projects, the absorption of capital surpluses and the ongoing economic crisis. It starts with the conceptualization of large urban projects in the light of the new role of cities in the contemporary world economy. Then it turns to considerations about the real estate dynamics and the conflicts involving urban land use and urban rent, and finally, it highlights the essential role of the State - in all geographic scales but, mainly, at the national level - at fixing parameters for territorial arrangement, principles of integrated regional policy, and enforcing the public regulation of urban space.

K E Y W O R D S Large urban projects; capital surpluses; urban policy; National State; urban land. 